\title{
Household waste separation intention and the importance of public policy
}

\author{
Bing Chen and Jiwon Lee \\ ELM Graduate School, HELP University, Kuala Lumpur, Malaysia
}

\begin{abstract}
Purpose - The key challenge that urban cities in most developing and transitional economies is confronting is municipal solid waste (MSW) management. Waste separation is a critical component to successful recycling management in terms of enhancing the quality of recyclables, reducing MSW and optimizing incineration. The urge to actualizing sustained waste separation behavior has been hindered by potential barriers. This study aims to examine the influences of external and internal stimuli of targeted households' waste separation intention in parts of China.

Design/methodology/approach - A multifactor framework predicting the process that leads to waste separation attitude and behavioral intention is proposed. SEM analysis is conducted in SmartPLS based on 371 survey questionnaires collected in Nanning city in China.

Findings - Policy regulation is the biggest determinant of attitude among external stimuli, while awareness of consequence has the strongest relationship with an attitude among internal stimuli. Facilitating conditions, subjective norms and moral norms are all significant predictors of attitude. As a result, increasing positive attitude leads to enhance waste separation lifestyle.

Research limitations/implications - This study adopts a cross-sectional design to investigate the waste separation intention of local households. Data collection is restricted to one point in time for every individual. A mixed method is recommended. Quantitative research can examine variables provided in existing literature with numerical analysis. Qualitative research might be helpful to identify other unknown factors. Also, the survey questionnaires employ a self-reported manner, and respondents might be overrating to avoid embarrassment.

Practical implications - Future research is recommended to engage observation at houses or at the wastecollecting points for actual waste separation behavior. Moreover, this study measures intention toward household waste separation, but whether this intention will eventually lead to waste separation behavior is not a guarantee. Future study is recommended to examine whether intention translates into actual waste separation behavior.

Originality/value - Emphasizing the importance of policy element as a direct influence toward attitude, this paper focuses on the waste separation attitude accumulated from external and internal stimuli, and, concurrently, waste separation behavioral intention is influenced by accumulated attitudes. The study provides relevant policy development information of three Asian countries to enhance their present and future policy directions for a sustainable household waste separation management process
\end{abstract}

Keywords Municipal solid waste, Household waste separation intention, External stimuli, Internal stimuli, Municipal governments

Paper type Research paper (c) Bing Chen and Jiwon Lee. Published in International Trade, Politics and Development. Published by Emerald Publishing Limited. This article is published under the Creative Commons Attribution (CC BY 4.0) license. Anyone may reproduce, distribute, translate and create derivative works of this article (for both commercial and non-commercial purposes), subject to full attribution to the original publication and authors. The full terms of this license may be seen at http://creativecommons.org/licences/by/4.0/ legalcode

This study is financially supported by Guangxi Middle-aged and Young Teachers' Basic Ability Improvement Project (2018KY0735) and Nanning University Associate Professor Cultivation Project (2018JSGC08).
Received 31 March 2020

Revised 27 April 2020

Accepted 1 May 2020

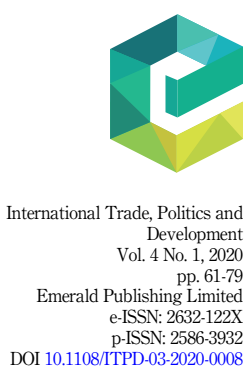


ITPD

4,1

\section{2}

\section{Introduction}

Municipal solid waste (MSW) is one of the life-threatening issues. The key challenge of MSW management confronting urban cities in most developing and transitional economies has become a priority for governments all over the world (Sukholthaman and Sharp, 2016). Currently, the world generates approximately 1.3 billion tons of MSW a year and is expected to increase to 2.2 billion tons by 2025 (World Bank, 2012). We need to predict the pollution output levels and at the same time have the abilities to manage waste in countries.

One of the key solutions is recycling. It will reduce MSW, as waste separation is a critical component to a successful recycling management in terms of enhancing the quality of recyclables, and will optimize incineration (Zhuang et al., 2008). The government has promoted the importance of recycling to the general public, and some developed countries have already achieved success in recycling. For instance, MSW recycling rate in Singapore was $61 \%$, South Korea $58 \%$, Iceland $55.8 \%$, Australia $42.1 \%$, Germany $47.8 \%$, Belgium $34.3 \%$ and the USA $34.6 \%$ (Kaza et al., 2018). However, developing countries still produce a million ton of MSW. Governments from developing countries have tried implementing waste separation policy, but these policies cannot be a success without the keen participation of households in a continuous act of waste separation processes.

To dwell deeper into the understanding the participation of households in waste separation schemes, previous studies have been conducted various analyses. Researchers found that demographic factors such as socio-economic background or dwelling types (Berglund, 2006; Vicente and Reis, 2008), or influence of personal characteristics such as education, awareness of consequence or moral norm (Williams and Taylor, 2004; Shirahada and Fisk, 2014) result in waste separation behavioral patterns, where the majority of them directly connect internal stimuli to their waste separation behavioral decision.

On the other hand, behavioral decision can be better explained as a result caused by external stimuli such as punishment, economic incentives (i.e. cash, vouchers, discount coupons and goods) (Bernstad, 2014; Shirahada and Fisk, 2014) or society influences (Xu et al., 2017).

Although several studies suggested a strong direct relationship between such factors and waste separation behavior, practitioners or public policy-makers knew there would be difference between their expectation and the reality about household's attitude and their behavioral intention toward waste separation management. According to the $\mathrm{ABC}$ theory (attitude, behavior and conditions), closer facilitating condition will result in high participation rates, independent of attitudes, while inadequate accessibility will result in low participation rate despite the positive attitude toward waste separation (Hage et al., 2008). Behavioral attitude and intention toward waste separation are different, and hence this study will focus on the waste separation attitude accumulated from external and internal stimuli and on waste separation behavioral intention which is influenced by accumulated attitudes.

Among external stimuli, the interesting stimulus is the extent an individual accepts the policy and the perceived effectiveness of policies designed to promote such proenvironmental behaviors, which, in turn, would also influence the intention to engage in waste separation behavior. Especially, China is a country with strong centralized power, and the top-down authority has issued a series of public policies which are meant to guarantee the success of sustainable waste separation management. Public policy is a very important driving force to trigger people's environmental behavioral change. However, even with a strong authority like China trying to enforce waste separation policies, the separation of waste is not happening at the ground level.

In this context, this study examines the possibility of active participation in waste separation through the investigation of the external and internal stimuli of targeted household in parts of China where 190 million tons of MSW is produced, which accounts for $29 \%$ of the world's MSW (The World Bank, 2012). China is supported with an authoritarian 
central government, which might guarantee the success of a sustainable waste separation management. The issue here is bringing MSW to ground-level acceptance and immersion. The results of this study will provide relevant authorities in China and other developing countries with information to enhance their present and future policy directions for a sustainable household waste separation management process.

\section{Literature review}

\subsection{Waste management policies in Asia}

Waste management is a life-threatening issue, and waste management needs to become more sustainable; it needs to be environmentally effective, economically affordable and socially acceptable (McDougall, 2005). Source separation for recycling is one of the most crucial methods to achieving sustainable household waste management. Most countries especially in Asia, despite intense efforts to cultivate waste separation behavior, continue to grapple with the low level of source separation practice. Under current situation, separating waste at source requires a behavioral change, and regulative element is essential so that government authorities aim to achieve an increase in correctly sorted recyclables and a decrease in missed-sorted waste through their public policy (Sukholthaman and Sharp, 2016).

2.1.1 Waste management policy in Malaysia. The ABC Plan (Action Plan for a Beautiful and Clean Malaysia) in 1987 was a notion of the beginning of national waste management plan in Malaysia (Moh, 2017). This plan attempts to decrease waste generation but has no specific legal instrument to actualize it. With the lead of ABC Plan, two more recycling programs were introduced in 1993 and 2000 (Moh, 2017). But these recycling programs did not transfer into sustained waste separation or recycling behavior. With the introduction of the Solid Waste and Public Cleansing Management Act 2007(also known as ACT 672), municipal solid waste (MSW) management is now standardized and obligatory waste separation and recycling is officially promoted in Peninsular Malaysia since 2011 (Fauziah et al., 2012; Moh, 2017).

In order to carry out the mandatory waste separation by households, the SWCorp Strategic Plan 2014-2020 is introduced (Moh, 2017). This comprehensive plan develops eight core strategies to realize and consolidate waste management step by step. These steps are to be executed by order (1) to change public's mindset toward building a cleaner environment, (2) to establish sustainable 3R behavior and culture, (3) to improve solid waste management services and public cleansing, (4) to actualize policy enforcement and regulation, (5) to ensure financial resources stability, (6) strengthen waste management technology system and facilities, (7) to strengthen law enforcement and (8) to strengthen delivery system (SWCorp Malaysia, 2014; Moh, 2017). However, without appropriate supporting system, facilities and equipment, this comprehensive strategic plan cannot be properly implemented. Thus, the promotion of citizen's source separation of household waste in Malaysia is still an unfilled plan.

2.1.2 Waste management policy in Korea. With persistent efforts for the last three decades, Korea's overall recycling rate for all wastes is as high as $80 \%$, and the total generation of household waste per person is as little $1 \mathrm{~kg} /$ day. (Yang et al., 2015). The accomplishment of this success begins with the establishment of Environmental Protection Agency and the introduction of Environmental Protection Law in 1978 (Yang et al., 2015). Consequently, the Waste Management Law was enacted in 1986 to integrate different waste management systems into one, and this laid the foundation of waste classification for further development. Currently, a series of amendments are made to actualize the 3Rs and waste separation for recycling. These amendments include Act on Resource Saving and Recycling Promotion (1992), Act on Waste Treatment Facilities Promotion and Support Surrounding Area (1995) and amendment of separating collection of recyclables (Yang et al., 2015).

\section{Household waste separation intention}


ITPD

4,1

\section{4}

Due to the separate treatments toward household waste and industrial wastes, the law for which was enforced in 1996, and the introduction of the volume-based garbage rate system (i.e. households have to pay to discharge waste by weight), household waste generation has dropped rapidly and sustains at $1 \mathrm{~kg} /$ day since 1995 (Yang et al., 2015). Overall, the success of waste management in Korea can be attributed to the implementation of a series of waste management laws and continuous efforts on enforcement of specialized acts. In order to target toward a zero-waste society in the future, new laws are in the planning stage.

2.1.3 Waste management policy in China. China's urbanization is a great success on many counts. However, the massive shift to consumeristic lifestyle has also produced tremendous waste, which is increasing with the population growth. "China surpassed the US as the world's largest waste generator in 2004 (World Bank, 2012)." Central government in China has attached unparalleled importance to household waste separation implementation. Beijing, Shanghai, Nanjing, Hangzhou, Guilin, Guangzhou, Shenzhen and Xiamen were first chosen to promote household waste separation in 2000.

After 19 years of effort, the results have indicated that pilot programs failed to encourage active participation at source separation in these cities. The Chinese government intensified its effort by introducing the "Domestic Waste Separation System Implementation Plan" in 2017, which called for the obligatory implementation of waste separation in 46 cities (Xiao et al., 2018). The government of China has shown great determination to achieve sustainable household waste management. This plan stated that compulsory waste separation needs to be implemented; the targeted recycling rate of domestic waste is about $35 \%$ by the end of 2020. In addition, a system of laws, regulations and standards related to waste separation should be established in every targeted city.

\subsection{Household recycling and waste separation}

2.2.1 Waste separation intention. Household participation is essential to the success of a waste separation scheme. Whether individuals are willing to engage in such scheme is measured by waste separation intention. Intention is the sole predictor for behavior in the theory of planned behavior (TPB) and often described as an "attempt to perform a behavior" (Ajzen, 1985). There are five basic constructs in TPB: attitude, subjective norm, perceived behavioral control, intention and behavior. It implies that a person's act is a deliberative process which is determined by one's intention and perceived behavioral control. Ajzen (1985) described intention as an "immediate determinant (p. 12)" of an action that is preceded by three psychological determinants, which are attitude, subjective norm and perceived behavioral control. The TPB connects cognitive and normative variables to explain people's intention and behavior.

Intention is also a predictor of behavior in Triandis' interpersonal behavior model (Triandis, 1977) and is defined as "a conscious plan to carry out a behavior." Intention links the cognitive constructs and behavior performance of an individual together (Pee et al., 2008). Intention has been found to be an important factor accounting for waste separation behavior in previous studies (Ofstad et al., 2017; Zhang, Huang, et al., 2015). However, intention does not always predict the actual performance of behavior (Kumar, 2012; Chung and Leung, 2007). To investigate how psychological and cognitive factors relate to household's waste separation intention, there is a need to understand the decision-making process behind these.

Numerous studies have identified relationship between attitude, subjective norms, perceived behavioral control and intention by adopting the psychological TPB framework (Karim Ghani et al., 2013; Stoeva and Alriksson, 2017; Khan et al., 2019; Lizin, Tonglet et al., 2004; Van Dael and Van Passel, 2017; Liao et al., 2018). Some researchers pointed out that the role of attitude seemed to be more prevalent in determination of intention (Barr et al., 2013). According to Shove (2010), the ABC model (attitude-behavior-choice) suggests a rational, 
linear and, more importantly, a simplistic approach to understand intention. A person's attitude toward targeted behavior is constituted by one's experience, understanding, knowledge and conception about a certain behavior. As a result, attitude can be determined by various factors. These factors, in sum, will lead to a positive or negative attitude toward targeted behavior in general. Thus, this study undertakes the attitude-intention approach to investigate the waste separation decision-making process of households.

2.2.2 Attitude toward waste separation. Waste separation attitude is the subjective assessment an individual holds toward waste separation. There is ample support that attitude is a strong predictor for intention. Stoeva and Alriksson (2017) found that strong positive attitude toward waste separation leads to waste separation at home among 223 students from Sweden and Bulgaria. Attitude is found to significantly influence residents' willingness to pay for improving recycling facilities in a study in Thailand (Vassanadumrongdee and Kittipongvises, 2018). Karim Ghani et al. (2013) also find significant evidence to support that positive attitude was the best determinant to predict intention to practice waste separation at home. Chen and Tung's (2010) study also supports a positive significant relationship between attitude and intention to recycle. Recent waste separation study confirmed that attitude is a significant determinant toward intention (Liao et al., 2018). In other words, positive attitude toward waste separation tends to lead to higher intention to act in the future. Thus, this study postulates the following hypothesis:

H1. Attitude toward waste separation has positive impact on intention to waste separation.

\subsection{Motivation of waste separation}

Waste separation is not a new concept in developed economies. However, it is a newly enforced scheme promoted in developing economies. Waste separation requires behavioral changes by all participants. Behavioral change theories suggest that motivations are essential to reinforce people's attitude, and thus leads to changes of behavior. Researchers argue that motivation can come from both internal and external stimuli (González Pérez et al., 2000; Haddad et al., 1981; Virvilaite et al., 2011). In studies of waste separation, studies have shown that external stimuli such as accessibility to waste separation facilities, monetary incentives and policy regulations are equally important as psychological stimuli derived from one's cognitive perceptions (Bernstad, 2014; Hage et al., 2008).

Unlike waste separation schemes in developing economies, the public in developed countries is familiar with knowledge of waste separation and internally motivated to participate in source separation. Furthermore, facilities for separation provided by governments have been developed into a more adequate level in terms of both quality and quantity. In contrast, in developing economies, waste separation schemes are still at an immature stage, and there are several barriers to the realization of waste separation. For instance, citizens have not fully accepted the concept of waste separation yet, many external motivational instruments are not properly provided by government and households are not skilled in waste separation. To realize the successful promotion of waste separation schemes in China, it is not only important to understand the decision-making process of intention, but it is also vital to distinguish whether these influencing elements are internal or external, so as to design specific policy interventions to eliminate existing barriers.

Thus, this study develops a research framework combing external and internal stimuli as motivational determinants of one's waste separation attitude, and ultimately how these factors are reflected in households waste separation intention.

2.3.1 External stimuli of waste separation. 2.3.1.1 Policy regulation. The purpose of proenvironmental public policy is to stimulate pro-environmental intentions and actual behavioral change (Steg and Vlek, 2009). Recycling, waste separation and other programs
Household waste separation intention 
ITPD

4,1

66

that involve behavioral change to encourage pro-environmental behavior are often the purpose of public policy. As a country in which political power is strongly centralized, the topdown waste separation schemes of China's local governments are expected to be successful. However, despite intense efforts to cultivate waste separation behavior, many cities continue to grapple with a low level of source separation. Despite the waste separation opportunities provided, people do not participate in the program. As the focus of this study is on households who carry out the actual waste separation at source, it is important to understand residents' perceptions of the waste separation policy implemented by the Chinese government. Residents' perceptions could, in turn, influence their attitude to engage in pro-environmental actions.

The effectiveness of policy intervention was introduced into waste separation studies in recent years. Policy regulation measures the perceived effectiveness of waste separation policy by participants of an environmental scheme. Wan et al. (2014) reported the positive direct relationship between perceived policy effectiveness and intention to separate waste in Hong Kong. Liao et al. (2018) also reported a positive relationship between PPE and waste separation intention in rural areas in China. Steg and Vlek (2009) pointed out that polices interventions can be targeted to influence person's attitude. If an individual considers the waste separation policies as effective or if they are in favor of current waste separation policies, their attitude would be positive and will encourage them to their participate. Hence, the following hypothesis is proposed:

H2a. Policy regulation has positive influence on attitude to separate waste at source.

2.3.1.2 Incentives. Economic incentives are measures often introduced to promote environmental behavior. Economic theory assumes that individuals are rational economic persons and their decisions are driven by reasonable evaluation of costs and benefits. The introduction of incentives acts as a motivational device for individuals to re-evaluate the cost of action. Incentives generally include rewards and punishments. Researchers state that economic incentives in recycling and in plastic waste collection are significant influencing factors that households react to (Thogersen, 2003; Hage et al., 2008). Studies suggest that rewards are usually more effective to facilitate pro-environmental action (Geller, 2002; Steg and Vlek, 2009). Yau (2010) records that economic incentives work well to promote waste recycling in Hong Kong. A survey in Hong Kong reported that households were willing to return batteries on the condition that refundable deposit was promised. On the other hand, Scott (1999) did not find evidence to support that economic incentive significantly influences recycling.

In the current study, incentive scheme has not yet been introduced in Nanning city. The draft of regulation of introducing incentive measures on waste separation is still under discussion. There is a need to understand whether people favor incentive plans which will be enforced in the near future. This study investigates the impact of incentive plans on waste separation attitude. Thus, the following hypothesis is formulated:

H2b. Incentives have positive impact on attitude toward waste separation.

2.3.1.3 Facilitating conditions. Waste separation relies heavily on external conditions. The ABC theory (attitude, behavior and conditions) provided by Hage et al. (2008) suggest that without accessibility to recycling facilities, participation rate drops even in presence of positive attitude and high environmental awareness. Barr et al. (2013) and Bernstad (2014) assert that households' low participation rate in recycling is the result of constraints from external condition. Researchers pointed out that external constraints need to involve time, space and the convenience of recycling channels (Karim Ghani et al., 2013). Facilitating conditions in this study represent external constraints that facilitate or impede the intention to perform a specific behavior. Chang and Cheung (2001) reported facilitating conditions 
established a positive and significant influence on intention to use the Internet at work. Facilitating conditions were found to positively impact intention to use Internet banking (Zolait, 2014). In a pro-environmental study (Liao et al., 2018), facilitating conditions positively influenced intention to separate takeaway waste. In this study, it is assumed that with satisfactory external conditions, households' positive attitude toward waste separation will be stimulated. Hence, this study proposes that:

H2c. Facilitating conditions have positive impact on attitude toward waste separation.

Household waste separation intention

2.3.1.4 Subjective norm. In the TPB model, subjective norm refers to "the perceived social pressure to perform or not to perform the behaviour (Ajzen, 1991, p. 188)." More specifically, it refers to the social pressure an individual perceives from his/her significant others, that is, family members, friends, partner and colleagues. Subjective norm is determined by normative beliefs that if a person's important others consider he/she should perform certain behavior, and he/she is motivated to comply with the social referents, then there is positive influence on subjective norm. Several studies recorded positive influence of subjective norm on intention, including waste separation intention (Tonglet et al., 2004; Xu et al., 2017; Vassanadumrongdee and Kittipongvises, 2018; Chen and Tung, 2010) and household food waste reduction intention (Graham-Rowe et al., 2015). On the other hand, a person's attitude can be influenced by normative values of his/her social contacts. Hence, the following hypothesis is proposed:

H2d. Subjective norm has positive impact on attitude toward waste separation.

2.3.2 Internal stimuli of waste separation. Moral norm represents ethical concerns and perceived social responsibility associated with behaving in a pro-social manner. Moral norms are strongly internalized moral values; the stronger these moral values, the stricter the discipline applied to the self in terms of behavior. In behavioral studies, moral norm is often found to be an influential determinant on intention in behavior related to moral concerns. For instance, in pro-environmental behaviors, Botetzagias et al. (2015) reported that moral norms significantly influence attitude toward recycling. Chan and Bishop (2013) documented moral norm as a significant predictor of recycling attitude. A recent waste separation study which tests perceived moral obligation (PMO) as an antecedent of attitude found that PMO is a significant predictor of attitude (Xu et al., 2017). Hence, the following hypothesis is proposed:

H3a. Moral norm has positive impact on attitude toward waste separation.

2.3.2.1 Self-efficacy. Self-efficacy represents the individual's perceived knowledge and effectiveness of performing targeted behavior and is one component of perceived behavioral control. The more knowledge about a specific action that one possesses, the more control and confidence one perceives. Previous studies show some connections between self-efficacy and behavioral intention through experiments and experimental tests. Jugert et al. (2016) conducted four experiments in Germany and Australia to show that self-efficacy was a fundamental basis to raise collective efficacy, and as a result to stimulate pro-environmental intentions. Sheeran et al. (2016) reviewed 204 experimental tests and concluded that changes in self-efficacy could lead to changes in health-related intention. Some researchers found direct influence of self-efficacy and intention through path analyses. A strong and significant effect of self-efficacy on recycling was documented in Spain (Taverners and Hernández, 2011). Hagger et al. (2001) reported a positive influence of self-efficacy on intention to participate in physical activity. Zolait (2014) confirmed that self-efficacy had direct influence on customer intentions to use Internet banking. High self-efficacy indicates that one is confident to have internal control over his/her action and thus leads to positive attitude to perform certain behavior. Hence, the following hypothesis is proposed: 
ITPD

4,1

68

$H 3 b$. Self-efficacy has positive impact on attitude toward waste separation.

2.3.2.2 Awareness of consequence. Awareness of consequence is operationally defined as "an individual's knowledge of expected outcomes of waste separation." Comprehensive knowledge of the outcomes of actions or behavior can shape a person's understanding of the expected results. Chen and Tung (2010) report that the consequences of recycling positively influence consumers' intention to recycle. Wan et al. (2014) state that awareness of consequence showed positive influence on recycling intention. A recent study in Bangkok reported that awareness of consequence showed significant positive influence on source separation intention (Vassanadumrongdee and Kittipongvises, 2018). Tonglet et al. (2004) noted that awareness of consequence represents the affective (experiential) element of attitude. Hence, the following hypothesis is proposed:

H3c. Awareness of consequence has positive impact on attitude toward waste separation.

Based on the discussion, this study aims to establish the following research model (see Figure 1). External stimuli are motivational elements derived from external without one's control, which include policy regulation, incentives, facilitating condition and subjective norm. Internal stimuli are motivations originating from one's internal values, controls and cognition, which include moral norm, self-efficacy and awareness of consequence. This model proposes that these external and internal stimuli combine and influence individual's attitude together and, in turn, affect one's intention to separation waste.

\section{Research methodology}

\subsection{Sample selection and measures}

We proposed a framework predicting the process that leads to waste separation attitude and behavioral intention. The questionnaire is designed based on measurement items for all

Figure 1.

Research model in current study

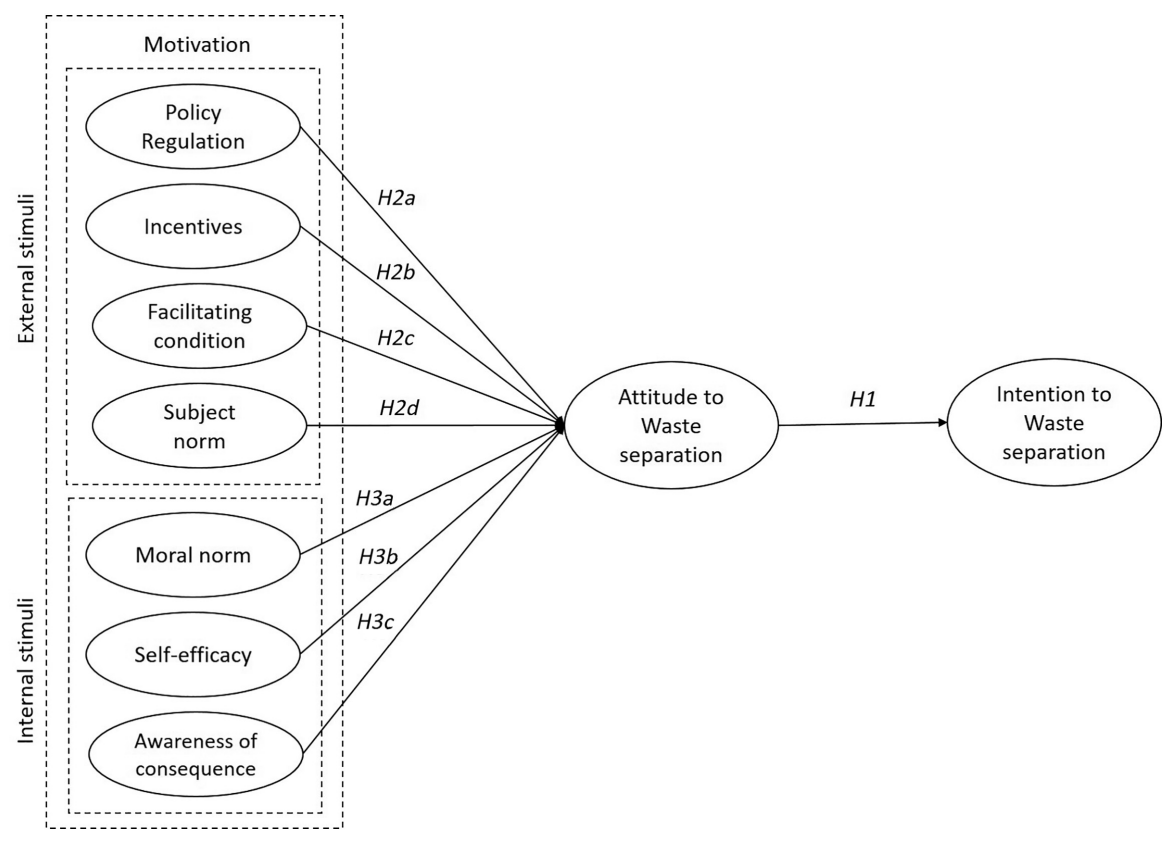


constructs in the research framework. There are nine variables in total in the research framework: attitude, subjective norm, self-efficacy, facilitating condition, moral norm, awareness of consequence, incentives, policy regulation and intention to separate waste at source. All measurement items are adapted and modified from previous studies (Tylor and Todd, 1995; Chu and Chiu, 2003; Karim Ghani et al., 2013; Wan et al., 2014; Liao et al., 2018). All items are measured on a five-point Likert scale, ranging from 1: "strongly disagree" to 5: "strongly agree." The constructs and measurement items are tabulated in Table 1.

Data collection was conducted in Nanning city, the capital of Guangxi Zhuang Autonomous Region in China. It is located in the southern central part of Guangxi. Total area of the city is $9,835 \mathrm{~km}^{2}$, with urban population about 3.32 million in 2017 (Nanning statistics yearbook, 2018). There are two major MSW processing facilities, with a daily processing capability of 3,200 tons. Local government has been promoting household waste separation scheme since 2014. It is also one of the 46 cities targeted in the domestic waste separation system implementation plan in 2017. The city has been progressing waste separation scheme to a number of residential communities since 2014. This scheme has covered about 768,000 households in the urban area in Nanning by October 2019 (Ling, 2019).

Following consultations from waste separation office in Nanning city, three residential communities were selected and permitted to distribute questionnaires. Data collection was conducted in July 2019. Questionnaires were distributed to households at the entrance of every residential community. The entire process of data collection was legal and complied with ethics requirements. Printed surveys were prepared, together with information letter and consent form. In order to avoid response bias, every respondent was notified that the survey was voluntary, anonymous and confidential. Those who are willing to fill out the questionnaire gave consent for the use of the survey information for aggregate analysis only. Questionnaires were pilot-tested and revised for final distribution.

A total of 579 questionnaires were collected. Among them, 371 were used for the analyses in this study. Among 371 respondents, $125(33.7 \%)$ were male and $246(66.3 \%)$ were female. With regard to respondents' age, majority of them were in their 30 s $(45 \%)$ and 40 s $(35 \%)$, whereas those under $30 \mathrm{~s}(11.1 \%)$ and above $50 \mathrm{~s}(8.9 \%)$ were few. In terms of education level, $212(57.1 \%)$ acquired an undergraduate or equivalent degree, $124(33.4 \%)$ acquired a high school or equivalent degree, $28(7.5 \%)$ had primary and secondary school degree and $7(1.9 \%)$ acquired postgraduate degree. Regarding the size of household, majority of them had three or more members; $109(29.4 \%)$ had three members, $155(41.8 \%)$ had four household member and $68(18.3 \%)$ more than 5 members. Detailed demographic information is tabulated in Table 2.

\subsection{Measure validation}

The research model has eight constructs with interrelated dependence relationships or causal paths, requiring a structural equation modeling (SEM) analysis. SEM analysis requires constructs to be assessed rigorously to examine convergent and discriminant validity. PLSSEM was chosen as data analysis method in the sample since this technique helps to provide prediction of target variables or identification of key drivers (Hair et al., 2017). Path coefficient results were obtained using the software package SmartPLS.

3.2.1 Reliability and convergent validity. The assessment metrics provided for internal consistency reliability are Cronbach's alpha $(\alpha)$ and composite reliability (CR). Factor loadings values (also called indicator reliability) and average variance extracted (AVE) are criterions for convergent validity. The reliability value above 0.7 is satisfactory for both Cronbach's alpha and composite reliability tests. As shown in Table 3, Cronbach's alpha values range from 0.783 to 0.929 , indicating satisfactory reliability for all constructs. The CR values are also satisfactory, ranging from 0.852 to 0.955 . The factor loading values for all items are above 0.7 , indicating each item is positively correlated with each other and
Household waste separation intention 
ITPD 4,1

\section{0}

Incentives

Facilitating condition

Subjective norm

Moral norm

Self-efficacy

Awareness of consequence

Attitude to waste separation

Intention to waste separation

Table 1.

Measurement items

\begin{tabular}{|c|c|c|c|}
\hline Construct & Item & Measurement items & Researchers \\
\hline \multirow[t]{3}{*}{ Policy regulation } & PR1 & $\begin{array}{l}\text { The separation facilities (bins, waste collection pools) } \\
\text { provided by the government are sufficient to facilitate } \\
\text { separation }\end{array}$ & \multirow[t]{3}{*}{ Liao et al. (2018) } \\
\hline & PR2 & $\begin{array}{l}\text { The government provides clear guidelines and examples } \\
\text { on separation }\end{array}$ & \\
\hline & PR3 & $\begin{array}{l}\text { The government's promotion clearly explains the benefits } \\
\text { of separation }\end{array}$ & \\
\hline \multirow[t]{3}{*}{ Incentives } & $\mathrm{INC1}$ & $\begin{array}{l}\text { I am in favor of imposing economic rewards to facilitate } \\
\text { waste separation }\end{array}$ & \multirow[t]{3}{*}{ Miranda (1994) } \\
\hline & $\mathrm{INC2}$ & $\begin{array}{l}\text { I am in favor of imposing credit points to record } \\
\text { household waste separation performance }\end{array}$ & \\
\hline & INC3 & $\begin{array}{l}\text { I am in favor of imposing fines on inadequate household } \\
\text { waste separation performance }\end{array}$ & \\
\hline Facilitating & $\mathrm{FC} 1$ & There is enough space for me to separate my waste at & Karimet al. (2013) \\
\hline
\end{tabular}

Taylor and Todd (1995)

FC2 I have time to separate my waste at home

FC3 I have convenient access to waste separation bins

SN1 Most people who are important to me think I should do waste separation

SN2 Most people who are important to me would approve of my waste separation behavior

SN3 My neighbors expect me to separate household waste

SN4 My friends expect me to separate household waste

SN5 My family expects me to separate household waste

SN6 My co-workers or schoolmates expect me to separate household waste

MN1 I feel I should not waste anything if it could be used again Wan et al. (2014)

MN2 It would be wrong of me not to separate my household waste

MN3 I would feel guilty if I did not separate my household waste

MN4 Not separating household waste goes against my principles

SE1 I know what waste should be separated

SE2 Knowing what waste should be separated is an important part of my decision whether to engage in this behavior

SE3 I know how to separate waste effectively

$\mathrm{AC1}$ Waste separation reduces wasteful use of landfills

AC2 Waste separation conserves natural resources

AC3 Waste separation improves environmental quality

$\mathrm{AC} 4$ Waste separation saves energy

AC5 Waste separation saves money

AT1 Waste separation is good

AT2 Waste separation is good

AT3 Waste separation is rewarding

AT4 Waste separation is responsible

AT5 Waste separation is sensible

AT6 Waste separation is hygienic

AT7 Waste separation is beneficial

INT1 I intend to separate my household waste in the near future

INT2 I will separate my household waste every time I have it for disposal

INT3 I am willing to participate in the separation scheme in the near future

Wan et al. (2014)
Chu and Chiu

(2003)

Wan et al. (2014)

Liao et al. (2018)

Wan et al. (2014) 


\begin{tabular}{|c|c|c|c|c|}
\hline & Category & Frequency & $(\%)$ & Househol \\
\hline \multirow[t]{2}{*}{ Gender } & Male & 125 & $33.7 \%$ & separatio \\
\hline & Female & 246 & $66.3 \%$ & separate \\
\hline \multirow[t]{4}{*}{ Age } & $18-30$ & 41 & $11.1 \%$ & intentio \\
\hline & $31-40$ & 167 & $45 \%$ & \\
\hline & $41-50$ & 130 & $35 \%$ & \\
\hline & $>50$ & 33 & $8.9 \%$ & 71 \\
\hline \multirow{4}{*}{ Education level } & Primary and secondary school & 28 & $7.5 \%$ & \\
\hline & High school and equivalent & 124 & $33.4 \%$ & \\
\hline & Undergraduate and equivalent & 212 & $57.1 \%$ & \\
\hline & Postgraduate & 7 & $1.9 \%$ & \\
\hline \multirow{5}{*}{ Household size } & 1 & 1 & $0.3 \%$ & \\
\hline & 2 & 38 & $10.2 \%$ & \\
\hline & 3 & 109 & $29.4 \%$ & Tabl \\
\hline & 4 & 155 & $41.8 \%$ & Demographic \\
\hline & $\geq 5$ & 68 & $18.3 \%$ & data $(N=371)$ \\
\hline
\end{tabular}

representing common concept of the same variable (Hair et al., 2017). The AVE value is above 0.5 for each construct. The outer loadings and AVE together demonstrate satisfactory convergent validity for all nine variables in this study.

3.2.2 Discriminant validity. For assessing discriminant validity in variance-based SEM, the result of heterotrait-monotrait ratio (HTMT) is provided. Its prominent sensitivity guarantees that it is effective to recognize the lack of discriminant validity (Henseler et al., 2015). As suggested by Hair et al. (2017) and Henseler et al. (2015), the bootstrap confidence intervals of HTMT statistics are reported in Table 4. All heterotrait-monotrait correlations are below conservative threshold value of 0.85 . Moreover, all confidence interval values are below value 1 . Therefore, it is safe to conclude that the results establish discriminant validity in this study.

\section{Empirical analysis}

\subsection{Assessment of collinearity issues}

The VIF values were calculated by using consistent PLS algorithm with factor weighting scheme and 300 maximum iteration. All constructs display values less than the threshold VIF value of 5, which indicates there was no critical level of collinearity in this study (Hair et al., 2017) (see Table 5).

\subsection{Hypothesis test result}

As shown in Figure 2, there are six significant relationships indicated in the path coefficient results. Five relationships are statistically significant at 1\% level, and one relationship is significant at $5 \%$ level. Attitude has a positive impact on intention to separate waste at source ( $\mathrm{H} 1$ is supported), with a coefficient of $0.47(p<0.01)$, which is the strongest correlation among all eight relationships. H2a that suggested a positive association between policy regulation and attitude is supported, with the coefficient of $0.297(p<0.01)$. Policy regulation is the strongest determinant among external stimuli elements. H2c proposes a positive relationship between facilitating conditions and attitude, and the coefficient of $0.181(\phi<0.01)$ indicates the result is statistically significant. So H2c is supported. Subjective norm displays a significant impact on attitude, with a coefficient of $0.148(p<0.01)$; H2d is supported.

On the other hand, moral norm among internal stimuli is positively related to attitude with a coefficient of 0.146 ( $p<0.01)$; thus, H3a is supported. Also, awareness of consequence displayed a positive significant relationship with attitude ( $\mathrm{H} 3 \mathrm{c}$ is supported), with a 


\section{ITPD}

4,1

\begin{tabular}{|c|c|c|c|c|c|}
\hline Variable & Items & Factor loadings & Cronbach's alpha & $\mathrm{CR}$ & AVE \\
\hline \multirow[t]{3}{*}{ Policy regulation } & PR1 & 0.826 & \multirow[t]{3}{*}{0.823} & \multirow[t]{3}{*}{0.894} & \multirow[t]{3}{*}{0.738} \\
\hline & PR2 & 0.874 & & & \\
\hline & PR3 & 0.876 & & & \\
\hline \multirow[t]{3}{*}{ Incentives } & $\mathrm{INC1}$ & 0.932 & \multirow[t]{3}{*}{0.926} & \multirow[t]{3}{*}{0.953} & \multirow[t]{3}{*}{0.870} \\
\hline & INC2 & 0.936 & & & \\
\hline & INC3 & 0.930 & & & \\
\hline \multirow[t]{3}{*}{ Facilitating condition } & $\mathrm{FC} 1$ & 0.732 & \multirow[t]{3}{*}{0.865} & \multirow[t]{3}{*}{0.902} & \multirow[t]{3}{*}{0.756} \\
\hline & $\mathrm{FC} 2$ & 0.922 & & & \\
\hline & $\mathrm{FC} 3$ & 0.939 & & & \\
\hline \multirow[t]{6}{*}{ Subjective norm } & SN1 & 0.700 & \multirow[t]{6}{*}{0.825} & \multirow[t]{6}{*}{0.872} & \multirow[t]{6}{*}{0.532} \\
\hline & SN2 & 0.762 & & & \\
\hline & SN3 & 0.702 & & & \\
\hline & SN4 & 0.715 & & & \\
\hline & SN5 & 0.772 & & & \\
\hline & SN6 & 0.724 & & & \\
\hline \multirow[t]{4}{*}{ Moral norm } & MN1 & 0.839 & \multirow[t]{4}{*}{0.926} & \multirow[t]{4}{*}{0.758} & \multirow[t]{4}{*}{0.926} \\
\hline & MN2 & 0.901 & & & \\
\hline & MN3 & 0.860 & & & \\
\hline & MN4 & 0.882 & & & \\
\hline \multirow[t]{3}{*}{ Self-efficacy } & SE1 & 0.829 & \multirow[t]{3}{*}{0.789} & \multirow[t]{3}{*}{0.876} & \multirow[t]{3}{*}{0.703} \\
\hline & SE2 & 0.846 & & & \\
\hline & SE3 & 0.840 & & & \\
\hline \multirow[t]{5}{*}{ Awareness of consequence } & $\mathrm{ACl}$ & 0.708 & \multirow[t]{5}{*}{0.783} & \multirow[t]{5}{*}{0.852} & 0.535 \\
\hline & $\mathrm{AC} 2$ & 0.706 & & & \\
\hline & $\mathrm{AC} 3$ & 0.718 & & & \\
\hline & $\mathrm{AC4}$ & 0.749 & & & \\
\hline & AC5 & 0.775 & & & \\
\hline Attitude to waste separation & AT1 & 0.767 & 0.862 & 0.894 & 0.545 \\
\hline & AT2 & 0.724 & & & \\
\hline & AT3 & 0.711 & & & \\
\hline & AT4 & 0.742 & & & \\
\hline & AT5 & 0.735 & & & \\
\hline & AT6 & 0.752 & & & \\
\hline & AT7 & 0.738 & & & \\
\hline Intention to waste separation & INT1 & 0.939 & 0.929 & 0.955 & 0.876 \\
\hline & INT2 & 0.946 & & & \\
\hline & INT3 & 0.922 & & & \\
\hline
\end{tabular}

coefficient of $0.272(p<0.01)$. Awareness of consequence is the largest internal motivational element toward attitude in current model. Surprisingly, two relationships are not statistically significant. First, the relationship between incentives and attitude is not significant, with coefficient of -0.05 ( $\phi=0.143)$; H2b is not supported. Second, self-efficacy has a coefficient of 0.017 ( $p>0.407)$; hence, H3b is not supported.

In summary, there are interesting findings in this study. Policy regulation is the biggest determinant of attitude among external stimuli, and awareness of consequence has the strongest relationship with attitude among internal stimuli. In addition, facilitating condition, subjective norm and moral norm are also significant predictors of attitude toward waste separation. Attitude and intention to separate waste at source have the strongest relationship among all eight path coefficient results (see Table 6).

\section{Discussion and limitations}

The effect of two different stimuli aiming at increasing waste separation behavioral intention was assessed through an empirical study in Nanning city residential area in China. Nanning 


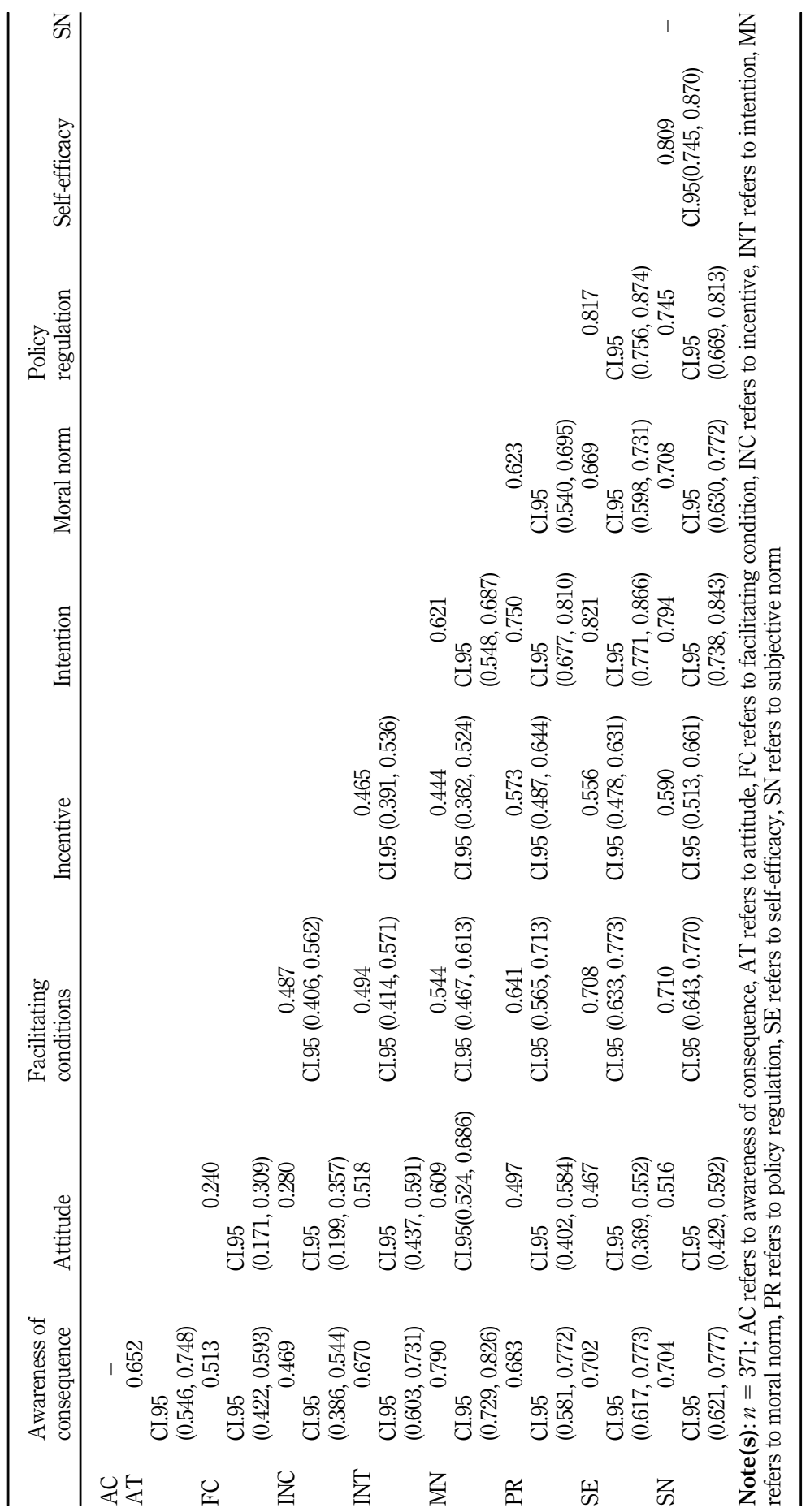

Household waste separation intention

73

Table 4. Discriminant validity for HTMT 
ITPD

4,1

74

city has been experimentally promoting waste separation scheme in selected residential communities since 2014. The implementations of waste separation policy have been on and off at times. The experimental scale was small for the first two years, and the outcomes were not desirable. New adjustments were made gradually, and the experimental sites were expanded to more residential communities in the past few years. From the empirical results, we drew several intellectual important points of discussion.

First, this study divided determinants that affect the waste segmentation, into two different stimulations. Waste separation at source is subjectively done by individuals collecting recyclable or compostable materials and placing them at the disposal locations near their household (Sukholthaman and Sharp, 2016). Thus, voluntary participation is the vital key of success in waste separation; thus, we divide the factors of attitude toward waste separation into external stimuli from environment and internal stimuli by a person.

Second, among the relationships between external stimuli and attitude, policy regulation is the biggest determinant of attitude, while awareness of consequence has the strongest

Table 5.

Collinearity assessment

\begin{tabular}{lc}
\hline & \\
\hline Awareness of consequence & Attitude (VIF) \\
Facilitating conditions & 2.076 \\
Incentive & 1.968 \\
Moral norm & 1.510 \\
Policy regulation & 2.156 \\
Self-efficacy & 2.230 \\
Subjective norm & 2.400 \\
\end{tabular}

Figure 2.

Results of research model

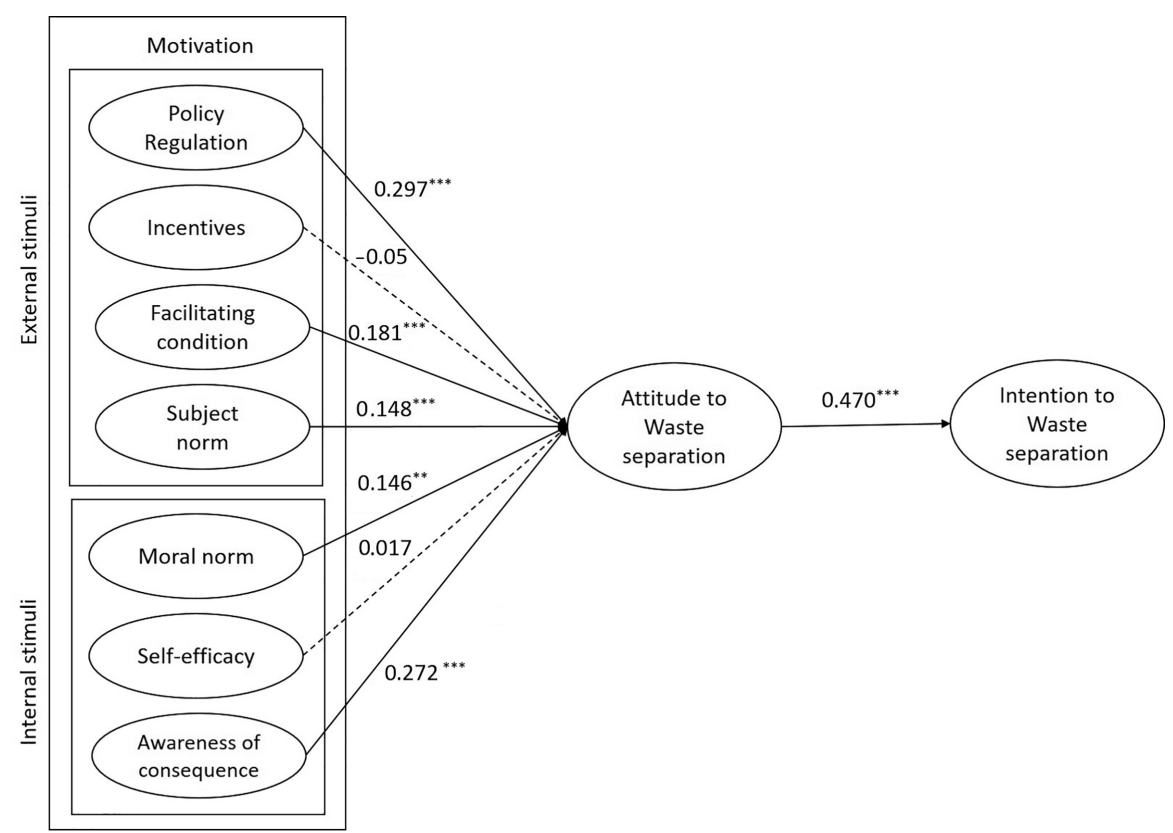

Note(s): ${ }^{* *} p<0.05,{ }^{* * *} p<0.01$ 


\begin{tabular}{|c|c|c|c|c|c|c|}
\hline & Coefficient & $\mathrm{SD}$ & $t$-value & $p$-value & Result & Househol \\
\hline Attitude $\rightarrow$ Intention & $0.470^{* * * *}$ & 0.043 & 10.922 & 0.000 & Supported & separc \\
\hline Policy regulation $\rightarrow$ Attitude & $0.297 * * *$ & 0.058 & 5.139 & 0.000 & Supported & \\
\hline Incentives $\rightarrow$ Attitude & -0.050 & 0.047 & 1.066 & 0.143 & Not supported & nte \\
\hline Facilitating conditions $\rightarrow$ Attitude & $0.181^{* * * *}$ & 0.052 & 3.475 & 0.000 & Supported & \\
\hline Subjective norm $\rightarrow$ Attitude & $0.148^{* * * *}$ & 0.062 & 2.396 & 0.008 & Supported & \\
\hline Moral norm $\rightarrow$ Attitude & $0.146^{* * *}$ & 0.072 & 2.038 & 0.021 & Supported & \\
\hline Self-efficacy $\rightarrow$ Attitude & 0.017 & 0.073 & 0.236 & 0.407 & Not supported & \\
\hline Awareness of consequence $\rightarrow$ Attitude & $0.272^{* * * *}$ & 0.071 & 3.811 & 0.000 & Supported & \\
\hline$R^{2}$ for Attitude & & & 0.385 & & & \\
\hline$R^{2}$ for Intention & & & 0.220 & & & \\
\hline $\operatorname{Note}(\mathbf{s}): * * p<0.05, * * * p<0.01$ & & & & & & Path c \\
\hline
\end{tabular}

relationship with attitude among internal stimuli. These findings have provided valuable implications to policy-makers. As a top-down public policy targeted to trigger proenvironmental behavioral change of citizens, at the early stage of a waste separation scheme, policy strategies ought to be designed to influence people's positive attitude toward waste separation. For instance, we can learn the success case of waste management in Korea. Korea government has implemented a series of waste management laws and exercised continuous efforts on enforcement of specialized acts so that waste separation behavior of Korean household has been changed slowly. This reflects that policy-makers should highlight the importance of waste separation to enlighten household, by implementing the strong policy regulation continuously.

Third, policy-makers ought to provide adequate facilities in both quantity and quality. Supply of sufficient facilities like waste containers should be guaranteed. Facilities like waste bins inside residential communities should be evenly distributed. Convenient access and usage of such facilities, as well as cleanness and maintenance of these facilities, is also very important.

Fourth, results from the present study can be seen as conflicting with several previous studies, suggesting that neither incentives nor self-efficacy has any significant influence on attitude toward waste separation. According to Ekvall et al. (2010), even though economic incentives on residual waste have been suggested as an interesting strategy in order to increase recycling (Bisaillon et al., 2009), policy-makers can see only a temporary effect. Moreover, the outcome of incentive is not necessarily positive, if resulting in illegal dumping. Also, such incentives are difficult to apply in multi-family, rental dwellings. It is hard to change the attitude toward waste separation habits.

Fifth, attitude toward the waste separation is a significant determinant of waste separation intention in this study. Even though households have positive attitude toward the waste separation, shown waste separation behavior could be different. This behavior has not yet developed into a high repetitive habitual routine. However, we found that increasing positive attitude led to enhancement of the behavioral intention of waste separation lifestyle.

\subsection{Limitation and future study}

This study adopts a cross-sectional design to investigate waste separation intention of local households. Data collection is restricted to one point in time for every individual. A mixed method is recommended. Quantitative research can examine variables which are provided in existing literatures with numerical analysis. Qualitative research might be helpful to identify other unknown factors. Also, the survey questionnaires employ a self-reporting manner. 
ITPD

4,1

Respondents might be overrating to avoid embarrassment. Future research is recommended to engage observation at houses or at the waste collecting points for actual waste separation behavior. Moreover, this study measures intention toward household waste separation, but whether this intention will eventually lead to waste separation behavior is not a guarantee. Future study is recommended to examine whether intention translates into actual waste separation behavior.

\section{References}

Ajzen, I. (1985), "From intentions to actions: a theory of planned behavior", Action Control: From Cognition to Behavior, Springer, pp. 11-39.

Ajzen, I. (1991), "The theory of planned behavior", Organizational Behavior and Human Decision Processes, Vol. 50 No. 2, pp. 179-211.

Barr, S., Guilbert, S., Metcalfe, A., Riley, M., Robinson, G.M. and Tudor, T.L. (2013), "Beyond recycling: an integrated approach for understanding municipal waste management", Applied Geography, Vol. 39, pp. 67-77.

Berglund, C. (2006), "The assessment of households' recycling costs: the role of personal motives", Ecological Economics, Vol. 56 No. 4, pp. 560-569.

Bernstad, A. (2014), "Household food waste separation behavior and the importance of convenience", Waste Management, Vol. 34 No. 7, pp. 1317-1323.

Botetzagias, I., Dima, A.F. and Malesios, C. (2015), "Extending the theory of planned behavior in the context of recycling: the role of moral norms and of demographic predictors", Resources, Conservation and Recycling, Vol. 95, pp. 58-67.

Chan, L. and Bishop, B. (2013), "A moral basis for recycling: extending the theory of planned behaviour”, Journal of Environmental Psychology, Vol. 36, pp. 96-102.

Chang, M.K. and Cheung, W. (2001), "Determinants of the intention to use Internet/WWW at work: a confirmatory study", Information and Management, Vol. 39 No. 1, pp. 1-14.

Chen, M.F. and Tung, P.J. (2010), “The moderating effect of perceived lack of facilities on consumers' recycling intentions", Environment and Behavior, Vol. 42 No. 6, pp. 824-844.

Chu, P.Y. and Chiu, J.F. (2003), "Factors influencing household waste recycling behavior: test of an integrated model", Journal of Applied Social Psychology, Vol. 33 No. 3, pp. 604-626.

Chung, S.S. and Leung, M.M.Y. (2007), "The value-action gap in waste recycling: the case of undergraduates in Hong Kong", Environmental Management, Vol. 40 No. 4, pp. 603-612.

Fauziah, S.H. and Agamuthu, P. (2012), "Trends in sustainable landfilling in Malaysia, a developing country", Waste Management and Research, Vol. 30 No. 7, pp. 656-663.

Geller, E.S. (2002), "The challenge of increasing proenvironment behavior", Handbook of Environmental Psychology, pp. 525-540.

González Pérez, P., Negrete Martínez, J., Barreiro García, A. and Gershenson García, C. (2000), “A model for combination of external and internal stimuli in the action selection of an autonomous agent”, Mexican International Conference on Artificial Intelligence 2000: Advances in Artificial Intelligence, Springer, pp. 621-633.

Graham-Rowe, E., Jessop, D.C. and Sparks, P. (2015), "Predicting household food waste reduction using an extended theory of planned behaviour", Resources, Conservation and Recycling, Vol. 101, pp. 194-202.

Haddad, N.F., Walkenbach, J., Preston, M. and Strong, R. (1981), "Stimulus control in a simple instrumental task: the role of internal and external stimuli”, Learning and Motivation, Vol. 12 No. 4, pp. 509-520.

Hage, O., Sandberg, K., Söderholm, P. and Berglund, C. (2008), "Household plastic waste collection in Swedish municipalities: a spatial-econometric approach". 
Hair, J.F. Jr, Hult, G.T.M., Ringle, C. and Sarstedt, M. (2017), A Primer on Partial Least Squares Structural Equation Modeling (PLS-SEM), Sage publications, Los Angeles.

Henseler, J., Ringle, C.M. and Sarstedt, M. (2015), "A new criterion for assessing discriminant validity in variance-based structural equation modelling", Journal of the Academy of Marketing Science, Vol. 43 No. 1, pp. 115-135.

Jugert, P., Greenaway, K.H., Barth, M., Büchner, R., Eisentraut, S. and Fritsche, I. (2016), "Collective efficacy increases pro-environmental intentions through increasing self-efficacy", Journal of Environmental Psychology, Vol. 48, pp. 12-23.

Karim Ghani, W.A.W.A., Rusli, I.F., Biak, D.R. and Idris, A. (2013), "An application of the theory of planned behaviour to study the influencing factors of participation in source separation of food waste", Waste Management, New York, NY, Vol. 33 No. 5, pp. 1276-1281.

Kaza, S., Yao, L., Bhada-Tata, P. and Van Woerden, F. (2018), What a Waste 2.0: A Global Snapshot of Solid Waste Management to 2050, World Bank, Urban Development, Washington, DC.

Khan, F., Ahmed, W. and Najmi, A. (2019), "Understanding consumers' behavior intentions towards dealing with the plastic waste: perspective of a developing country”, Resources, Conservation and Recycling, Vol. 142, pp. 49-58.

Kumar, B. (2012), Theory of Planned Behaviour Approach to Understand the Purchasing Behaviour for Environmentally Sustainable Products, No. WP2012-12-08, Indian Institute of Management Ahmedabad, Research and Publication Department.

Liao, C., Zhao, D. and Zhang, S. (2018), "Psychological and conditional factors influencing staff's takeaway waste separation intention: an application of the extended theory of planned behavior", Sustainable Cities and Society, Vol. 41, pp. 186-194.

Liao, C., Zhao, D., Zhang, S. and Chen, L. (2018), "Determinants and the moderating effect of perceived policy effectiveness on residents' separation intention for rural household solid waste", International Journal of Environmental Research and Public Health, Vol. 15 No. 4, pp. 726-743.

Ling, J.Y. (2019), "Waste separation in Nanning city covers 768,000 households", Nanning Evening Newspaper, available at: http://www.nnwb.com:8080/tbarticle.do?

Miranda, M.L., Everett, J.W., Blume, D. and Roy, B.A. Jr (1994), "Market-based incentives and residential municipal solid waste", Journal of Policy Analysis and Management, Vol. 13 No. 4, pp. 681-698.

Moh, Y. (2017), "Solid waste management transformation and future challenges of source separation and recycling practice in Malaysia”, Resources, Conservation and Recycling, Vol. 116, pp. 1-14.

Ofstad, S.P., Tobolova, M., Nayum, A. and Klöckner, C.A. (2017), "Understanding the mechanisms behind changing people's recycling behavior at work by applying a comprehensive action determination model", Sustainability, Vol. 9 No. 2, p. 204.

Pee, L.G., Woon, I.M. and Kankanhalli, A. (2008), "Explaining non-work-related computing in the workplace: a comparison of alternative models", Information and Management, Vol. 45 No. 2, pp. $120-130$.

Scott, D. (1999), "Equal opportunity, unequal results: determinants of household recycling intensity", Environment and Behavior, Vol. 31 No. 2, pp. 267-290.

Sheeran, P., Maki, A., Montanaro, E., Avishai-Yitshak, A., Bryan, A., Klein, W.M. ... and Rothman, A.J. (2016), "The impact of changing attitudes, norms, and self-efficacy on health-related intentions and behavior: a meta-analysis”, Health Psychology, Vol. 35 No. 11, pp. 1178-1188.

Shirahada, K. and Fisk, R.P. (2014), "Chapter 5: service sustainability: a tripartite value cocreation perspective in progressive trends", in Kosaka, M. and Shirahada, K. (Eds), Progressive Trends in Knowledge and System-Based Science for Service Innovation, IGI Global, Pennsylvania, pp. 89-99.

Shove, E. (2010), "Beyond the ABC: climate change policy and theories of social change", Environment and Planning A, Vol. 42, pp. 1273-1285.

\section{Household waste separation intention}


ITPD

4,1

Steg, L. and Vlek, C. (2009), "Encouraging pro-environmental behaviour: an integrative review and research agenda”, Journal of Environmental Psychology, Vol. 29 No. 3, pp. 309-317.

Stoeva, K. and Alriksson, S. (2017), "Influence of recycling programmes on waste separation behaviour", Waste Management, Vol. 68, pp. 732-741.

Sukholthaman, P. and Sharp, A. (2016), "A system dynamics model to evaluate effects of source separation of municipal solid waste management: a case of Bangkok, Thailand", Waste Management, Vol. 52, pp. 50-61.

SWCorp Malaysia (2014), “SWCorp strategic plan (pelan strategik SWCorp) 2014 -2020”, available at: https://www.kpkt.gov.my/resources/index/user_1/Attachments/hebahan_slider/slaid_dapatan_ makmal.pdf.

Taylor, S. and Todd, P. (1995), "An integrated model of waste management behavior: a test of household recycling and composting intentions", Environment and Behavior, Vol. 27 No. 5, pp. 603-630.

Thøgersen, J. (2003), "Monetary incentives and recycling: behavioural and psychological reactions to a performance-dependent garbage fee", Journal of Consumer Policy, Vol. 26 No. 2, pp. 197-228.

Tonglet, M., Phillips, P.S. and Read, A.D. (2004), "Using the Theory of Planned Behaviour to investigate the determinants of recycling behaviour: a case study from Brixworth, UK", Resources, Conservation and Recycling, Vol. 41 No. 3, pp. 191-214.

Triandis, H.C. (1977), Interpersonal Behaviour, Brook/Cole, Monterey, CA.

Vassanadumrongdee, S. and Kittipongvises, S. (2018), "Factors influencing source separation intention and willingness to pay for improving waste management in Bangkok, Thailand", Sustainable Environment Research, Vol. 28 No. 2, pp. 90-99.

Vicente, P. and Reis, E. (2008), "Factors influencing households' participation in recycling", Waste Management and Research, Vol. 26 No. 2, pp. 140-146.

Virvilaite, R., Saladienė, V. and Žvinklytė, J. (2011), "The impact of external and internal stimuli on impulsive purchasing", Ekonomika ir vadyba, Vol. 16, pp. 1329-1336.

Wan, C., Shen, G.Q. and Yu, A. (2014), "The role of perceived effectiveness of policy measures in predicting recycling behaviour in Hong Kong”, Resources, Conservation and Recycling, Vol. 83, pp. 141-151.

Williams, I.D. and Taylor, C. (2004), "Maximising household waste recycling at civic amenity sites in Lancashire, England", Waste Management, Vol. 24 No. 9, pp. 861-874.

World Bank (2012), "What a waste: a global review of solid waste management, Urban development and local government unit", World of Banking, Washington DC.

Xiao, S., Dong, H., Geng, Y. and Brander, M. (2018), "An overview of China's recyclable waste recycling and recommendations for integrated solutions", Resources, Conservation and Recycling, Vol. 134, pp. 112-120.

Xu, L., Ling, M., Lu, Y. and Shen, M. (2017), "Understanding household waste separation behaviour: testing the roles of moral, past experience, and perceived policy effectiveness within the theory of planned behaviour", Sustainability, Vol. 9 No. 4, pp. 1-27.

Yang, W.S., Park, J.K., Park, S.W. and Seo, Y.C. (2015), "Past, present and future of waste management in Korea”, Journal of Material Cycles and Waste Management, Vol. 17 No. 2, pp. 207-217.

Yau, Y. (2010), "Domestic waste recycling, collective action and economic incentive: the case in Hong Kong”, Waste Management, Vol. 30 No. 12, pp. 2440-2447.

Zhang, D., Huang, G., Yin, X. and Gong, Q. (2015), "Residents' waste separation behaviors at the source: using SEM with the theory of planned behavior in Guangzhou, China", International Journal of Environmental Research and Public Health, Vol. 12 No. 8, pp. 9475-9491.

Zhuang, Y., Wu, S.W., Wang, Y.L., Wu, W.X. and Chen, Y.X. (2008), "Source separation of household waste: a case study in China", Waste Management, Vol. 28 No. 10, pp. 2022-2030. 
Zolait, A.H.S. (2014), "The nature and components of perceived behavioural control as an element of theory of planned behaviour", Behaviour and Information Technology, Vol. 33 No. 1, pp. 65-85.

\section{Further reading}

Chan, K. (1998), "Mass communication and pro-environmental behaviour: waste recycling in Hong Kong”, Journal of Environmental Management, Vol. 52 No. 4, pp. 317-325.

Chung, S.S. and Poon, C.S. (1996), "The attitudinal differences in source separation and waste reduction between the general public and the housewives in Hong Kong", Journal of Environmental Management, Vol. 48 No. 3, pp. 215-227.

Chung, S.S. and Poon, C.S. (2000), "A comparison of waste reduction practices and the new environmental paradigm in four southern Chinese areas", Environmental Management, Vol. 26 No. 2, pp. 195-206.

Lizin, S., Van Dael, M. and Van Passel, S. (2017). "Battery pack recycling: behaviour change interventions derived from an integrative theory of planned behaviour study", Resources, Conservation and Recycling, Vol. 122, pp. 66-82.

Oikonomou, V., Becchis, F., Steg, L. and Russolillo, D. (2009), "Energy saving and energy efficiency concepts for policy making", Energy Policy, Vol. 37 No. 11, pp. 4787-4796.

Schneider, A. and Ingram, H. (1990), "Behavioral assumptions of policy tools", The Journal of Politics, Vol. 52 No. 2, pp. 510-529.

Sparks, P., Guthrie, C.A. and Shepherd, R. (1997), "The dimensional structure of the perceived behavioral control construct", Journal of Applied Social Psychology, Vol. 27 No. 5, pp. 428-438.

Tabernero, C. and Hernández, B. (2011), "Self-efficacy and intrinsic motivation guiding environmental behavior", Environment and Behavior, Vol. 43 No. 5, pp. 658-675.

Terry, D.J. and O'Leary, J.E. (1995), "The theory of planned behaviour: the effects of perceived behavioural control and self-efficacy", British Journal of Social Psychology, Vol. 34 No. 2, pp. 199-220.

\section{Corresponding author}

Jiwon Lee can be contacted at: jiwon.lee@help.edu.my
Household waste separation intention

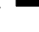

